\title{
Antonia S. Byatt, La morte di Lucien de Rubempré
}

\section{Marco Stupazzoni}

\section{(2) OpenEdition}

\section{Journals}

\section{Edizione digitale}

URL: http://journals.openedition.org/studifrancesi/36406

DOI: 10.4000/studifrancesi.36406

ISSN: 2427-5856

\section{Editore}

Rosenberg \& Sellier

\section{Edizione cartacea}

Data di pubblicazione: 1 juillet 2005

Paginazione: 184

ISSN: 0039-2944

\section{Notizia bibliografica digitale}

Marco Stupazzoni, «Antonia S. Byatt, La morte di Lucien de Rubempré», Studi Francesi [Online], 145 (XLIX | I) | 2005, online dal 30 novembre 2015, consultato il 20 avril 2021. URL: http:// journals.openedition.org/studifrancesi/36406 ; DOI: https://doi.org/10.4000/studifrancesi.36406

\section{Questo documento è stato generato automaticamente il 20 avril 2021.}

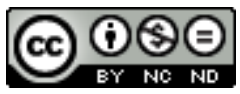

Studi Francesi è distribuita con Licenza Creative Commons Attribuzione - Non commerciale - Non opere derivate 4.0 Internazionale. 


\title{
Antonia S. Byatt, La morte di Lucien de Rubempré
}

\author{
Marco Stupazzoni
}

\section{NOTIZIA}

ANTONIA S. BYATT, La morte di Lucien de Rubempré, in AV. VV., Il romanzo. Volume quinto.

Lezioni, a cura di FRANCO MORETTI, PIER VINCENZO MENEGALDO e ERNESTO FRANCO, Torino, Giulio Einaudi editore, 2003, pp. 173-189.

1 Personaggio ambiguo e contraddittorio, Lucien de Rubempré conclude in modo tragico la sua tormentata esistenza in Splendeurs et misères des courtisanes. Dopo il primo tentativo di suicidio sventato in extremis da Vautrin in Illusions perdues, Lucien soccombe sotto il peso insostenibile della sua debolezza e della propria impotenza nel non saper trasformare le proprie illusioni in atti di forza (morali, psicologici e intellettuali) che gli avrebbero consentito, risolvendo e superando i contrasti tra provincia e Parigi, la frattura tra mondo poetico e mondo reale. Tentato (come Cristo) dalle forze demoniache del male e della corruzione incarnate da Vautrin, Lucien si mostra, contrariamente a Rastignac, vulnerabile: in questo senso, l'angelica bellezza della figura balzachiana non sarebbe altro che l'opaco riflesso della generale corruttibile debolezza dell'intero genere umano.

2 Le similitudini animali utilizzate da Balzac per scolpire il carattere dei suoi personaggi (maschili e femminili), il modello scientifico e le risonanze mistico-religiose che formano e attraversano le strutture e gli spazi della Comédie humaine conducono l'A. a riflettere sulla rappresentazione balzachiana del reale e sulla capacità (pressoché unica) dello scrittore di connettere tra loro la grandiosità e la stravagante proliferazione di persone, di indizi e di dettagli «nel tessuto di una prosa mutevole» (p. 188) che rispecchia il concerto stesso di comprensività balzachiana. Da questo punto di vista, la connessione alla Comédie di Illusions perdues e di Splendeurs et misères des 
courtisanes offre «ai lettori una chiave per capire in che modo Balzac costruiva la gigantesca volta e quindi gli schemi decorativi delle sue narrazioni» (p. 189). 